\title{
Islet cell transplantation transitioning to proven therapy for type 1 diabetes
}

\section{Se Young Kim}

Department of Pediatrics, Division of Pediatric Endocrinology, Bundang Jesaeng General Hospital, Dajin Medical Center, Seongnam, Korea
See the article "Pancreas transplant in type 1 diabetes mellitus: the emerging role of islet cell transplant" via https:// doi.org/10.6065/apem.2142012.006.
This article ${ }^{1)}$ focused on islet cell transplantation in children with type 1 diabetes as a realistic treatment. The author reviewed the indications, procedures and benefits of islet cell transplantation which is a core strategy to improve the outcome of the pediatric patient with type 1 diabetes.

In recent years, pancreatic islet cell transplantation is optimistically regarded as ultimate treatment regimen of type 1 diabetes. "Edmonton protocol" showed a monumental outcome. It was extended international study following previous report by Shapiro et al. ${ }^{2)}$ at the University of Alberta in Edmonton. In 2000, Shapiro et al. reported 7 consecutive type 1 diabetes patients with severe hypoglycemia and intact renal function who achieved 1-year insulin independence by pancreatic islet cell transplantation. The subsequent international clinical trial of the landmark "Edmonton protocol" reported a valuable clinical outcome: an $\sim 80 \%$ success rate of maintaining glycated hemoglobin levels less than $7.0 \%$ for 5 years without severe hypoglycemia. ${ }^{3)}$

Prior to these studies, islet autotransplantation for chronic pancreatitis patients refractory to conventional therapy was proven to be shown clinical benefits. Autotransplantation is free from immune rejection, recurrent autoimmunity, and the toxicity of immunosuppressants. ${ }^{4)}$

The major indications of pancreatic islet cell transplantation in adult patients are (1) allotransplantation in patients with type 1 diabetes under immunosuppressive therapy for kidney and/or liver transplantation, (2) with brittle diabetes carrying diabetic complications, and (3) with chronic pancreatitis suffering from intractable pain undergoing total pancreatectomy. Transplanted islet cells can promote the regeneration of endogenous $\beta$-cells. ${ }^{5)}$

As the author mentioned, islet cell transplantation began as an experimental therapy but is emerging to be quite beneficial decreasing surgical risk and complications. ${ }^{1)}$

We are faced with allogeneic islet cell transplantation for pediatric patients with type 1 diabetes. Allogeneic islet transplantation induces to improve glucose control for many years. ${ }^{6}$ Developed immunosuppressive therapy regimen ensure maintaining islet engraftment to prolonged graft function, reduction abrogation.

This therapy is predicted extension for patients with type 1 diabetes, both adult and children. In the future, multicentric studies on long-term follow-up results of transplanted pediatric patients with type 1 diabetes, is mandatory before it will be a routine therapeutic option.

\section{Conflict of interest}

No potential conflict of interest relevant to this article was reported.

\section{References}

1. Kochar IS, Jain R. Islet cell transplantation transitioning to proven therapy for type 1 diabetes. Ann Pediatr Endocrinol Metab 2021;26:86-91.

2. Shapiro AM, Lakey JR, Ryan EA. Islet transplantation in seven patients with type 1 diabetes mellitus using a glucocorticoid-free immunosuppressive regimen. N Engl J Med 2000;343:230-5.

3. Ryan EA, Paty BW, Senior PA. Five-year follow-up after clinical islet transplantation.

Se Young Kim

Department of Pediatrics, Division of Pediatric Endocrinology, Bundang Jesaeng General Hospital, Dajin Medical Center, 20 Seohyeon-ro 180beon-gil, Bundang-gu, Seongnam 13590, Korea

Email:smuf67@naver.com

https://orcid.org/0000-0003-49212795 
Diabetes 2000;54:2060-9.

4. Bruni A, Gala-Lopez B, Pepper AR, Abualhassan NS, Shapiro AJ. Islet cell transplantation for the treatment of type 1 diabetes: recent advances and future challenges. Diabetes Metab Syndr Obes 2014;7:211-23.

5. Jung HS, Ahn YR, Oh SH. Enhancement of beta- cell regeneration by islet transplantation after partial pancreatectomy in mice. Transplantation 2009;88:354-9.

6. Lablanche S, Borot S, Wojtuscizyn A. Five-year metabolic, functional, and safety results of patients with type 1 diabetes: a prospective 13-year follow-up. Diabetes Care 2015;38:752-9. 